\title{
Static secondary ion mass spectrometry (S-SIMS) analysis of atmospheric plasma treated polypropylene films
}

\author{
Bart Boschmans ${ }^{\mathrm{a}, *}$, Myriam Vanneste $^{\mathrm{b}}$, Luc Ruys ${ }^{\mathrm{b}}$, Eef Temmerman ${ }^{\mathrm{c}}$, \\ Christophe Leys ${ }^{c}$, Luc Van Vaeck ${ }^{\mathrm{a}}$ \\ ${ }^{a}$ Department of Chemistry, University of Antwerp (CDE), Universiteitsplein 1, B-2610 Wilrijk, Belgium \\ ${ }^{\mathrm{b}}$ Centexbel, Technologiepark 7, B-9052 Zwijnaarde, Belgium \\ ${ }^{\mathrm{c}}$ University of Ghent, Department of Applied Physics, Rozier 44, B-9000 Ghent, Belgium \\ Received 12 September 2005; accepted 15 February 2006 \\ Available online 9 May 2006
}

\begin{abstract}
Time-of-Flight (TOF) static secondary ion mass spectrometry (S-SIMS) was used to gain molecular information on the surface modifications introduced by plasma treatment of polypropylene (PP) films. A procedure using slotted electron microscopy grids was developed to deal with the charge build-up of samples with a thickness of about $30 \mu \mathrm{m}$. The surface composition was studied as a function of the plasma treatment time. A comparison of the mass spectra from untreated and treated PP showed significant differences of signal intensities of ions that could be specifically related to the presence of oxygen-containing species.
\end{abstract}

(C) 2006 Elsevier B.V. All rights reserved.

Keywords: TOF S-SIMS; Atmospheric plasma; Polypropylene; Charge build-up; Surface modification

\section{Introduction}

Atmospheric pressure plasma treatment of polymers can be used to tune surface properties and is intensively explored for the development of innovative textile materials [1,2]. However, the induced surface chemistry of the polymer is not well understood yet. The complexity of the system and the need to probe selectively the molecular composition of the outer few monolayers hamper experimental studies of polymer-plasma interactions. Although the latter requirement seems to suit the use of static secondary ion mass spectrometry (S-SIMS), only a few studies have been reported so far [3,4].

In an on-going project on the plasma treatment of hydrophobic polypropylene (PP) films to give them permanent hydrophilic properties, the feasibility to use S-SIMS to get information on the changes of surface functionalities and composition was studied. The analysis of as received samples with a thickness of about $30 \mu \mathrm{m}$ was a major challenge because the excessive charge buildup could not be compensated by the common methods, such as

\footnotetext{
* Corresponding author.

E-mail address: Bart.Boschmans@ua.ac.be (B. Boschmans).
}

low-energy electron flooding. Therefore, a new method for charge compensation was developed and tested. To get insight in the plasma-induced processes, fingerprinting was not adequate and structural interpretation of the mass spectra proved to be a demanding task, since plasma is known to potentially introduce several types of polar functional groups such as hydroxyl-, carboxyl- and amine-groups [3,5].

\section{Experimental}

The samples consisted of in-house manufactured PP films of approximately $30 \mu \mathrm{m}$ thickness. The films were cleaned with ethanol, dried and treated with air plasma, using a remote dc glow discharge at atmospheric pressure. The instrument is described elsewhere [6]. Samples were treated during 1.9, 3.1 and $5.9 \mathrm{~s}$ at a discharge power per exposed sample surface area of $0.58 \mathrm{~W} / \mathrm{mm}^{2}$.

To reduce charge build-up during S-SIMS analysis, a thin metal slot grid, consisting of nickel and with a slot of $500 \mu \mathrm{m}$ width and $2 \mathrm{~mm}$ length (SerCoLab, Merksem, Belgium), was pressed into the film using a standard pellet press and a pressure of $0.4 \mathrm{t} \mathrm{cm}^{-2}$ for $1 \mathrm{~min}$ and $1 \mathrm{t} \mathrm{cm} \mathrm{cm}^{-2}$ for $4 \mathrm{~min}$. A metal clip was used to connect the slot grid and SIMS sample holder. 
The S-SIMS analysis was performed with an ION TOF IV instrument (Cameca, Courbevoie, France), using $\mathrm{Ga}^{+}$primary ions of $25 \mathrm{keV}$. Positive ion mass spectra were recorded using a beam raster of $100 \mu \mathrm{m} \times 100 \mu \mathrm{m}$ inside the slot of the grid, an ion dose density of $7.5 \times 10^{12}$ ions $\mathrm{cm}^{-2}$ and an acquisition time of $600 \mathrm{~s}$. The $\mathrm{m} / \mathrm{z}$-scale was calibrated using the signals of $\mathrm{H}^{+}, \mathrm{CH}_{3}{ }^{+}, \mathrm{C}_{2} \mathrm{H}_{5}{ }^{+}$and $\mathrm{C}_{3} \mathrm{H}_{7}{ }^{+}$. Integration of the signals was performed using Poisson-correction. Signal intensities were normalised by the total ion counts of the spectra.

\section{Results and discussion}

The method of low-energy electron flooding was found to be inadequate to deal with the charge build-up of the thick nonconducting PP films during S-SIMS analysis with $\mathrm{Ga}^{+}$primary ions. Although polyatomic projectiles tend to reduce the problem, experiments with $\mathrm{SF}_{5}{ }^{+}$projectiles only delayed the onset of excessive charging compared to the use of monoatomic ions. Delcorte and Bertrand [7] proposed deposition of a gold layer to improve S-SIMS analysis. However, the mass spectra of untreated PP became identical to those of plasma treated PP. Apparently, the sputter-coating process, which also used a small plasma, masked the effects of the atmospheric plasma treatment to be studied. Therefore, a new charge compensation method was developed, using thin metal slot grids to surround the measurement area by conducting material. In this way, the surface charges in the vicinity of the slot are neutralized. As a result, PP films can be adequately analysed on the condition that an area close to the edge of the slot grid is rastered. However, mass resolution and mass accuracy remain inferior by a factor of about 2 to those obtainable for monolayers on flat conducting substrates or silicon wafers. Apart from residual charge build-up, some alteration of the extraction field could be responsible for this. In the latter case, the precise configuration of the pressed-in slit and the used ion extraction field can be important.

Fig. 1 compares the positive ion mass spectra of pristine and plasma treated PP. Virtually all diagnostic information is found in the range up to $\mathrm{m} / \mathrm{z}, 150$. The analysis of an area close to the nickel grid results in strong ${ }^{58} \mathrm{Ni}^{+}$and ${ }^{60} \mathrm{Ni}^{+}$signals as well as minor peaks due to $\mathrm{Fe}$ and $\mathrm{NiH}$ species. At first view, the mass spectra of treated and untreated PP look relatively similar. However, detailed analysis is needed to reveal the individual contributions of different ions at the same nominal $\mathrm{m} / \mathrm{z}$ and correctly assess the changes in ion intensities due to the plasma treatment. A typical example is given for $\mathrm{C}_{5} \mathrm{H}_{9} \mathrm{O}_{2}{ }^{+}$ions at $\mathrm{m} / \mathrm{z}$ 101 in the inset of Fig. 1.

The main intensity differences to be observed between pristine and plasma treated PP are found for the ions at $\mathrm{m} / \mathrm{z}, 55$, $57,69,71,83,101,105,107$ and 109, of which the relative difference increases by the exposure to the plasma. Interpretation of the signal intensity changes is facilitated by the structural assignment of these ions in Fig. 2. Most structures can be related to the oxidation of the pending methyl groups into carboxylic acids while some ions most likely refer to chain cleavage and formation of keto-functions on the secondary carbon. These mechanisms are consistent with literature findings $[5,7]$. The presence of oxygen-containing functionalities in the mass spectra of untreated PP spectra might be related
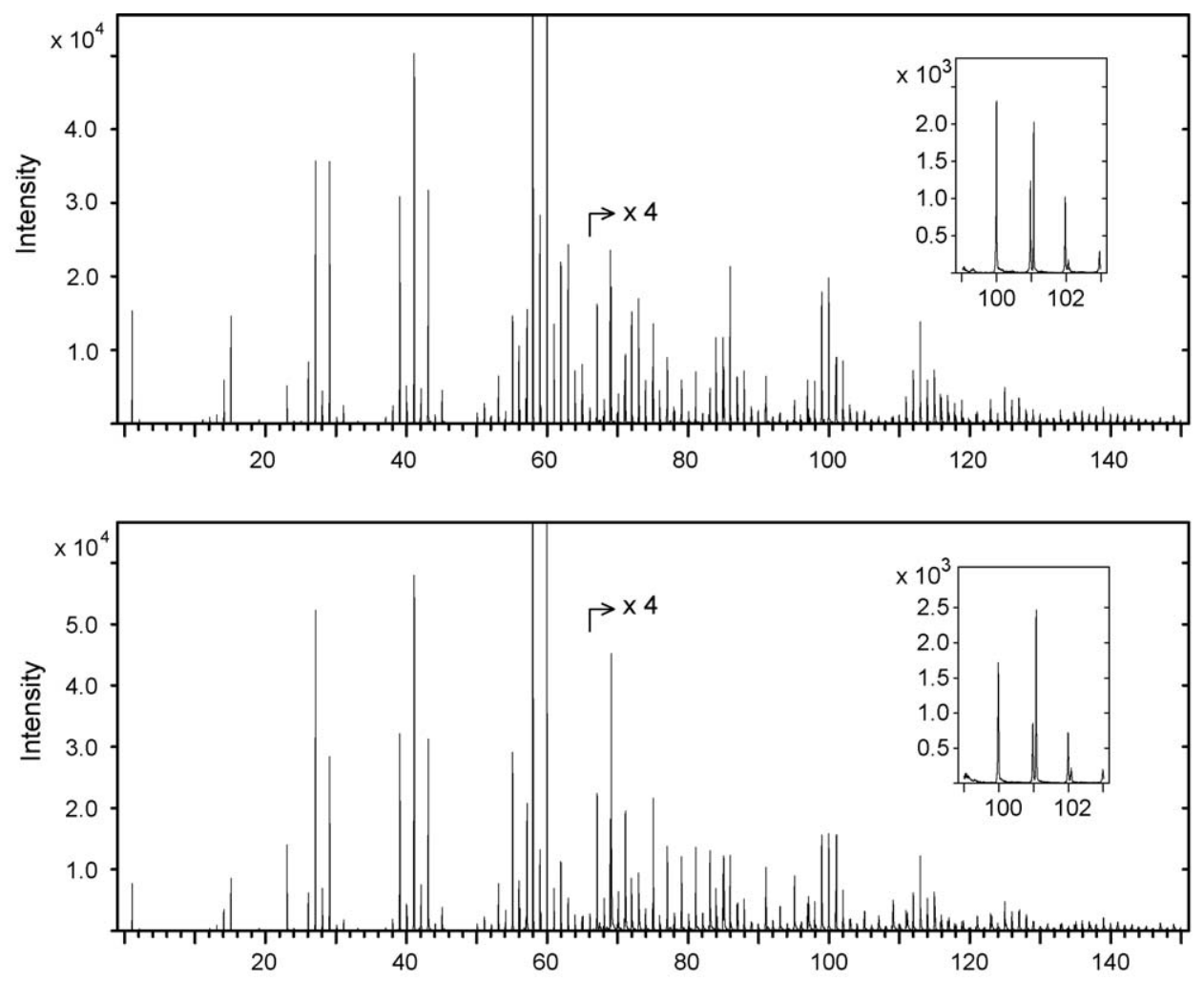

Fig. 1. The upper positive ion mass spectrum represents PP, the lower represents air plasma treated PP. Both are measured with the aid of a Ni metal slot grid. For convenience, the strong $\mathrm{Ni}^{+}$signals are cut off below their maximum. 

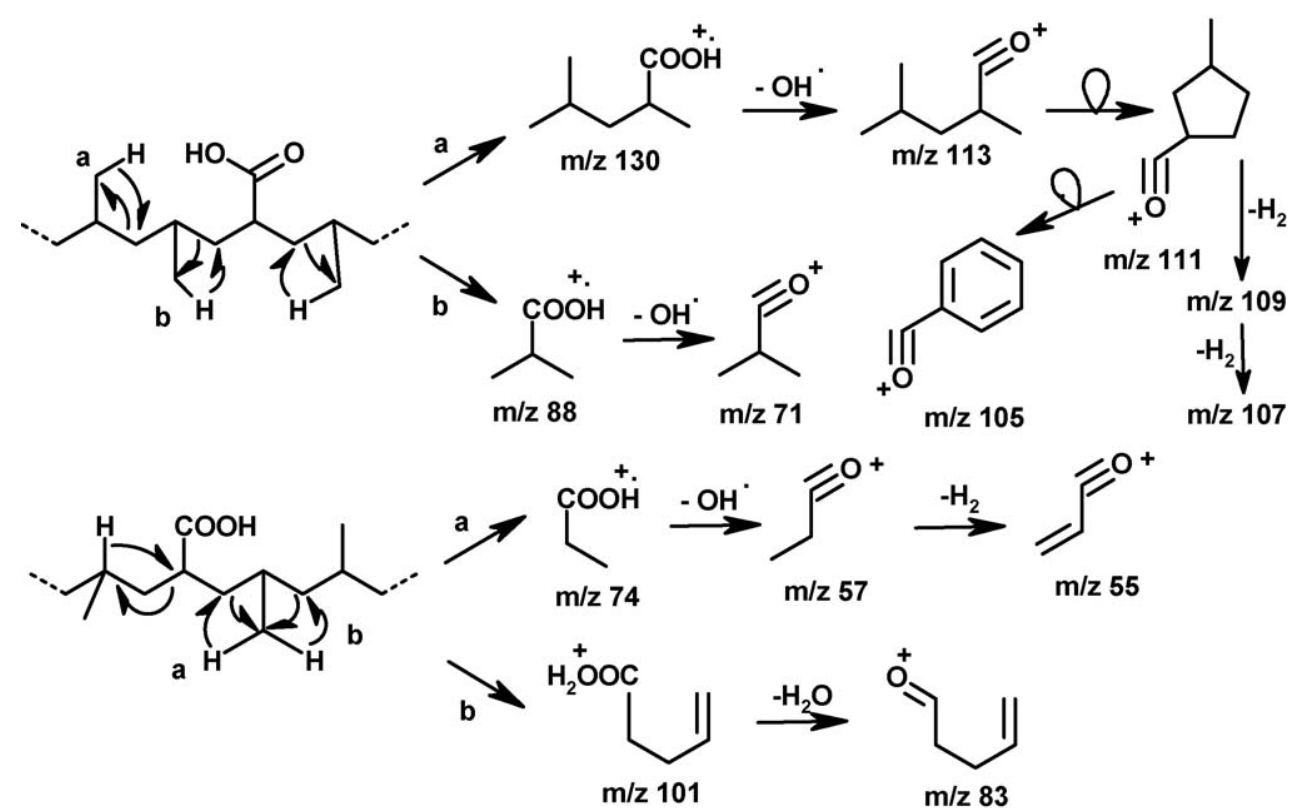

Fig. 2. Tentative fragmentation routes for PP with carboxylic acid groups implanted. The PP chain can fragment through four-center cleavages, which would often be followed by dissociation of the carboxylic acid group.

to prior oxidation of the ultimate surface. The mass spectra of pristine PP also contain several amine related ions (e.g. at $\mathrm{m} / \mathrm{z}$ $58,72,86,100$, etc.). The plasma treatment does not dramatically affect the relative importance of these ions.

Also important is the consistent trend of the ion intensities as a function of the plasma treatment time. Fig. 3 displays the normalised intensities of the oxygenated ions; the strongest increase is seen for the $\mathrm{C}_{2} \mathrm{H}_{3} \mathrm{O}^{+}$ions, of which the signal intensity changes by a factor 2 after $6 \mathrm{~s}$ of plasma treatment. Virtually all oxygen-containing species, such as $\mathrm{C}_{2} \mathrm{H}_{4} \mathrm{O}^{+}$, $\mathrm{C}_{2} \mathrm{H}_{5} \mathrm{O}^{+}$and $\mathrm{C}_{4} \mathrm{H}_{5} \mathrm{O}^{+}$, exhibit a similar trend, although the intensity gain by the plasma treatment is less pronounced than for the $\mathrm{C}_{2} \mathrm{H}_{3} \mathrm{O}^{+}$ions. Further investigations are needed to verify whether the strong increase of the signal intensity for the $\mathrm{C}_{2} \mathrm{H}_{3} \mathrm{O}^{+}$ions in comparison to that of the other oxygenated ions is related to the importance of the oxidation of the tertiary

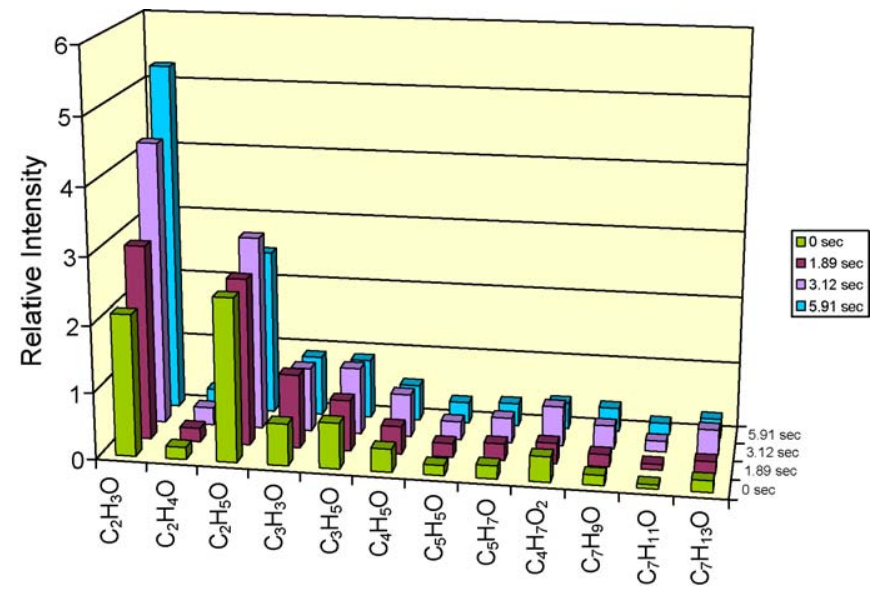

Fig. 3. Normalised intensities for selected ions for PP treated with air plasma during $0-6 s$.

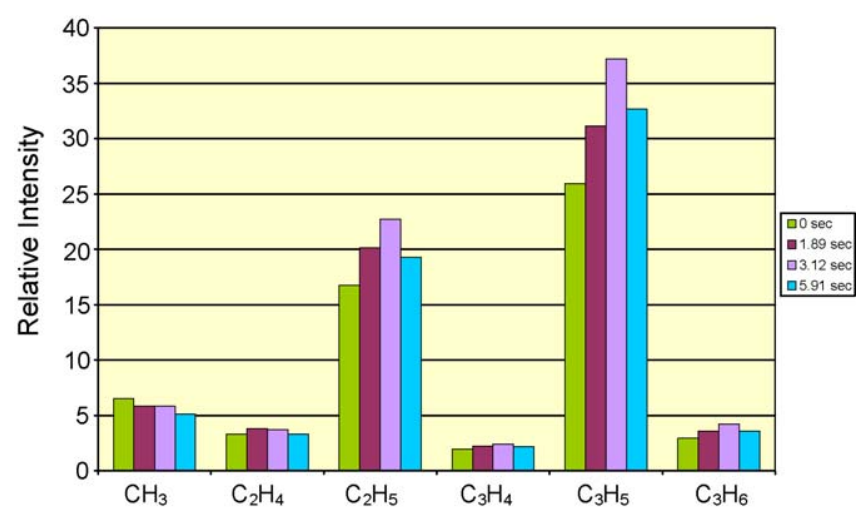

Fig. 4. Normalised intensities for selected low- $\mathrm{m} / \mathrm{z}$ ions with plasma treatment of $0-6 \mathrm{~s}$.

carbon compared to that of the primary carbon in PP. Next to ions with only one oxygen atom, there is also an increase of the signal intensity for the species containing two oxygen atoms.

Apart from the systematically increasing signal intensities for the oxygenated ions, plasma treatment seems to enhance the relative importance of low- $m / z$ hydrocarbon ions (Fig. 4). This trend is consistent with the expected surface damage, as consequence of the interaction with energetic ions and electrons from the plasma [8]. Particularly interesting is the decrease of the signal for the $\mathrm{CH}_{3}{ }^{+}$ions, which can be related to a conversion of the pending methyl groups into carboxyl groups.

\section{Conclusion}

The use of pressed-in metal slot grids provided a solution to deal with the charge build-up of thick PP films during S-SIMS analysis. As a result, the surface modifications of PP by atmospheric plasma could be probed qualitatively and quantitatively. The detected ions reflect formation of oxygen- 
functionalities at the pending groups and within the chain. Even the short treatment times $(<6 \mathrm{~s})$ were sufficient to change the surface composition significantly. The methodology may provide significant support for the use of atmospheric plasmas to produce novel PP materials with tuned hydrophilicity.

\section{Acknowledgements}

B. Boschmans acknowledges the UA for a grant from the Science Research Fund (BOF). This research was partially funded by the Flemish Institute for Scientific and Technological research (IWT), the Flemish Science Foundation (FWO Vlaanderen) and the Interuniversity Attraction Pole Program (IUAP V).

\section{References}

[1] P. Chaivan, N. Pasaja, D. Boonyawan, P. Suanpoot, T. Vilaithong, Surf. Coat. Technol. 193 (2005) 356-360.

[2] C. Tendero, C. Tixier, P. Tristant, J. Desmaison, P. Leprince, Spectrochim. Acta B 61 (2005) 2-30.

[3] N. Médard, M. Aouinti, F. Poncin-Epaillard, P. Bertrand, Surf. Interface Anal. 31 (2001) 1042-1047.

[4] E. Occhiello, F. Garbassi, M. Morra, Surf. Sci. 211-212 (1989) 218226.

[5] O.-J. Kwon, S. Tang, S.-W. Myung, N. Lu, H.-S. Choi, Surf. Coat. Technol. 192 (2005) 1-10.

[6] E. Temmerman, Y. Akishev, N. Trushkin, C. Leys, J. Verschuren, J. Phys. D: Appl. Phys. 38 (2005) 505-509.

[7] A. Delcorte, P. Bertrand, Appl. Surf. Sci. 231-232 (2004) 250-255.

[8] N. Medard, J.C. Soutif, F. Poncin-Epaillard, Langmuir 18 (2002) 22462253. 